\title{
The role of FFRCT in Aortic Surgery: Is this the future?
}

\author{
Abdul Ahmed ${ }^{1}$, Mohammed Idhrees ${ }^{2}$, and Mohamad Bashir ${ }^{3}$ \\ ${ }^{1}$ Macclesfield District General Hospital \\ ${ }^{2}$ SRM Institutes for Medical Science Vadapalani \\ ${ }^{3}$ Royal Blackburn Teaching Hospital
}

July 20, 2021

\section{Editorial}

The role of FFR $_{\mathrm{CT}}$ in Aortic Surgery: Is this the future?

Abdul Khaled Ahmed ${ }^{1}$, Mohammed Idhrees ${ }^{2}$, Mohamad Bashir ${ }^{3}$

1. Macclesfield District General, East Cheshire NHS Trust

2. Consultant, Institute of Cardiac and Aortic Disorders, SRM Institutes for Medical Science (SIMS Hospital), Chennai, India

3. Clinical Research Professor of Cardiovascular Surgery,

SRM Institutes for Medical Science (SIMS Hospital), Chennai, India

\section{Corresponding Author:}

Dr. A. Mohammed Idhrees MBBS, MS MCh, FAIS

Cardiovascular Surgeon

Institute for Cardiac and Aortic Disorders

SRM Institutes for Medical Science (SIMS Hospitals)

Chennai, India - 600026

Phone: +919962268787

E-Mail:a.m.idhrees@gmail.com

Key Words: FFRCT, Aortic dissection, Aortic aneurysm, Coronary artery

No. of words: 1115 (including references, abstract, title page)

No. of reference: 9

Conflict of Interest: Nil

Ethic committee clearance: N/A

Coronary artery disease (CAD) is not uncommon among patients who present with aortic aneurysm of the thoracic or abdominal aorta, as both diseases share a common aetiology. The prevalence of CAD in patients with abdominal aortic aneurysm is $31 \%$ to $90 \%$, descending thoracic aortic aneurysm is $51 \%$ and ascending aortic aneurysm is $20 \%(1,2)$. Considering the prevalence, it is of crucial importance that CAD has to be evaluated in these patients prior to intervention. 
But there are several questions which are yet to be evidently answered by the clinicians. What is the optimum investigation of choice to evaluate the CAD inpatients with aortic aneurysm? Is non-invasive investigations evaluation suffice for evaluation of CAD? Do we need to add CT coronary angiogram (CTCA) along with angiogram regularly? If there is a calcific coronary artery in CTCA, should the patient be subjected to invasive coronary angiogram (ICA)?

The current European Society of Cardiology (ESC) and the European Society of Anaesthesiology (ESA) guideline recommend preoperative CAG only for patients with two or more cardiac risk factors and poor functional capacity. The American and the Japanese Guidelines are no different (3-5). It is well documented that perioperative myocardial infarction has a significant negative impact on both early and late survival in these patients. Hence most of the aortic surgery units add CTCA during angiogram. CTCA has a very powerful negative predictive value but poor positive predictive value and is hobbled by artifacts like calcification. Such patients are then subjected to ICA. On the contrary, multiple observational studies have documented that only half of the suspected CAD patients have an invasively proven obstructive CAD $(5,6)$.

Noninvasive investigation can be broadly divided into 2 groups - functional (stress echocardiography, singlephoton emission, positron emission tomography, and stress cardiac MRI) and anatomic (CTCA). It is evident from above discussion that patients with aortic aneurysm with suspected CAD will require both functional and anatomical information. This mandates the patients need to undergo two separate non-invasive tests or a single invasive test (ICA with fractional flow reserve- FFR)

The newer technology Fractional flow reserve derived from CT $\left(\mathrm{FFR}_{\mathrm{CT}}\right)$ serves both simultaneously. FFR $\mathrm{CT}_{\mathrm{T}}$ is a computer-based technology that produces functional information from a CTCA derived anatomical model. FFR CT $_{\text {T }}$ has a better diagnostic ability as compared to CTCA for identifying stenosis in heavily calcified coronary arteries (7). Further is a useful adjudicated in intermediate stenosis found on CTCA.

The technology works on artificial intelligence. The method was developed by HeartFlow, Inc. and is currently the only FDA- and CE Mark-cleared FFR $\mathrm{CT}_{\mathrm{T}}$ technology. The software creates a three-dimensional (3D) anatomic model of the aorta and myocardium. For each vessel the resting and hyperemic microvascular resistance are quantified by the software. The computational fluid dynamics is utilised by the software, and a color-coded, 3D anatomic model with $\mathrm{FFR}_{\mathrm{CT}}$ values are generated for every location of the coronary tree. Functional significance is identified by combing the $\mathrm{FFR}_{\mathrm{CT}}$ with the patient-specific anatomic coronary map value is combined, functionally significant lesions can be identified (8)

This technology is approved in the U.S. and Europe, and is now recommended by NICE as an option for patients with stable, recent onset chest pain(9). The anatomical information coupled with functional assessment of the coronary artery will act as a gatekeeper, restricting patients with intermediate or significant stenosis with normal FFRCT from undergoing ICA. Utilizing this technology, NHS in England would save $£ 391 /$ patient and may save a minimum of $£ 9.4$ million by 2022 by avoiding invasive investigation and treatment (9).

Hence FFRCT can be combined with CT angiogram of the aorta. This will enable the surgeons to assess the CAD and manage appropriately depending upon the degree of stenosis. This can hopefully reduce the perioperative mortality in aortic surgery associated with CAD. The advantages would include (i) patient not subjected to an additional dose of contrast (ii) Single investigation to assess the functional and anatomical details of coronary artery (iii) Non-invasive investigation modality as compared to ICA (iv)Cost effectiveness to the health care system

\section{Reference}

1.Van Kuijk JP, Flu WJ, Dunckelgrun M, Bax JJ, Poldermans D. Coronary artery disease in patients with abdominal aortic aneurysm: a review article. J Cardiovasc Surg (Torino). 2009;50:93-107.

2. Kieffer E, Chiche L, Baron JF, Godet G, Koskas F, Bahnini A. Coronary and carotid artery disease in patients with degenerative aneurysm of the descending thoracic or thoracoabdominal aorta: prevalence and impact on operative mortality. Ann Vasc Surg. 2002. https://doi.org/10.1007/s10016-001-0315-1 
3. Kristensen SD, Knuuti J, Saraste A, et al. 2014 ESC/ESA Guidelines on non-cardiac surgery: cardiovascular assessment and management: The Joint Task Force on non-cardiac surgery: cardiovascular assessment and management of the European Society of Cardiology (ESC) and the European Society of Anaesthesiology (ESA). Eur Heart J. 2014. https://doi.org/10.1093/eurheartj/ehu282.

3. Fleisher LA, Fleischmann KE, Auerbach AD, et al. 2014 ACC/AHA guideline on perioperative cardiovascular evaluation and management of patients undergoing noncardiac surgery: a report of the American College of Cardiology/American Heart Association Task Force on Practice Guidelines. Circulation. 2014;130:e278333.

5. Kyo S, Imanaka K, Masuda M, et al. Guidelines for Perioperative Cardiovascular Evaluation and Management for Noncardiac Surgery (JCS 2014) - Digest Version. Circ J. 2017. https://doi.org/10.1253/circj.CJ-660135. 19. McFalls EO, Ward HB, Moritz TE, et al. Coronary-artery revascularization before elective major vascular surgery. N Engl J Med. 2004. https://doi.org/10.1056/NEJMoa041905.

5. Chinnaiyan KM, Raff GL, Goraya T, et al. Coronary computed tomography angiography after stress testing: results from a multicenter, statewide registry, ACIC (Advanced Cardiovascular Imaging Consortium). J Am Coll Cardiol. 2012;59:688-695.

6. Patel MR, Dai D, Hernandez AF, et al. Prevalence and predictors of nonobstructive coronary artery disease identified with coronary angiography in contemporary clinical practice. Am Heart J. 2014;167:846-852

7. Norgaard BL, Gaur S, Leipsic J, et al. Influence of coronary calcification on the diagnostic performance of CT angiography derived FFR in coronary artery disease: a substudy of the NXT trial. JACC Cardiovasc Imaging. 2015;8:1045-1055.

8.OMAR KHALIQUE, FFRCT: Why Should Interventional Cardiologists Care?. CARDIAC INTERVENTIONS TODAY. VOL. 13, NO. 3 MAY/JUNE 2019, 39-41.

9. https://www.nice.org.uk/guidance/mtg32/chapter/1-Recommendations 